\title{
DISSOCIATIVE IONIZATION OF CARBON DISULPHIDE IN THE GAS PHASE. HEAT OF FORMATION OF THE CS RADICAL
}

\author{
M.-J. HUBIN-FRANSKIN ${ }^{1}$, R. LOCHT and J. KATIHABWA \\ Institut de Chimie, Université de Liège, Sart Tilman par 4000, Liège 1, Belgium
}

\begin{abstract}
Measurements of the appearance potentials and the kinetic energies of $\mathrm{S}^{+}$and $\mathrm{CS}^{+}$ions formed by electron impact on carbon disulphide in the gas phase lead us to propose a value as low as $34 \pm 6 \mathrm{kcal}^{\text {mole }} \mathrm{e}^{-1}$ for the heat of formation of the CS radical in its ground electronic state. It is also shown that the predissociations of the $\mathrm{A}^{2} \Pi_{\mathrm{u}}$ /or $\mathrm{X}^{2} \Pi_{\mathrm{g}}$ and the $\mathrm{B}^{2} \Sigma_{\mathrm{u}}$ molecular ion states by a repulsive ${ }^{4} \Sigma^{-}$state giving rise to $\mathrm{S}^{+}$ions, observed through metastable ions study, occur at $13.45 \mathrm{eV}$ and $14.55 \mathrm{eV}$ respectively.
\end{abstract}

\section{Introduction}

A recent study of dissociative electron attachment processes in carbonyl sulphide [1] leads us to discuss the value of the heat of formation of the CS radical. A review of the literature data showed that the published values covered a range between $\leq 52.5 \mathrm{kcal} \mathrm{mole}^{-1}$ [2], deduced from the analysis of the chemi-luminescence of $\mathrm{CS}_{2}$ and $\mathrm{COS}$ reactions with metastable rare gas atoms, and $70 \mathrm{kcal}$ mole ${ }^{-1}$ [3], measured by a mass spectrometric study of the equilibrium $\mathrm{CS}_{2}+\mathrm{S} \rightleftharpoons \mathrm{CS}+\mathrm{S}_{2}$ in the gas phase. Determination of appearance potentials of $\mathrm{S}^{+}$and $\mathrm{CS}^{+}$formed by photon impact [4] leads to $\Delta H_{\mathrm{f}}(\mathrm{CS})=64.4 \mathrm{kcal} \mathrm{mole}^{-1}$ whereas by electron impact $[5,6]$ the value is $52.2 \mathrm{kcal} \mathrm{mole}^{-1}$. These results have to be considered as a higher limit since the amount of kinetic and internal energy involved in the processes studied is unknown. The dissociative electron attachment process for COS in the gas phase producing $\mathrm{O}^{-}$ions at $3.9 \mathrm{eV}$, recently studied [1], leads to a heat of formation as low as $32 \mathrm{kcal} \mathrm{mole}^{-1}$ for the CS radical.

The purpose of the present paper is to check this recent value of $\Delta H_{\mathrm{f}}(\mathrm{CS})$ by appearance potential and kinetic energy measurements of the $\mathrm{S}^{+}$and $\mathrm{CS}^{+}$ions formed by impact of $10-16 \mathrm{eV}$ electrons on carbon disulphide.

\section{Experimental}

The instrument as well as the experimental conditions used in the present work were described in detail elsewhere [7]. Briefly, the ions formed in a Niertype ion source are energy analyzed by a retarding lens before entering into a quadrupole mass spectrometer. The ion current can be continuously scanned either with respect to the retarding potential for a fixed electron energy or with respect to the electron energy for a fixed retarding potential. Both signals can be differentiated, stored in a multichannel analyzer and recorded on an $X$ - $Y$ recorder.

The carbon disulphide pressure is of the order of $5 \times 10^{-7}$ torr in the ion source. The first ionization potential of $\mathrm{CS}_{2}$ at $10.059 \pm 0.008 \mathrm{eV}$ [4] is used for the electron energy scale calibration ${ }^{2}$. The maximum of the thermal energy distribution of $\mathrm{CS}_{2}{ }^{+}$is taken as the origin of the kinetic energy scale.

\section{Results and discussion}

\subsection{Appearance potentials}

The appearance potentials of the $\mathrm{S}^{+}$and $\mathrm{CS}^{+}$ions are listed in table 1 and compared to the literature data. The minimum threshold energies are found at 13.35 and $14.5 \mathrm{eV}$ respectively; these values are considerably

\footnotetext{
1 "Chargé de Recherches" of the "Fonds National de la Recherche Scientifique".

2 The appearance potentials are determined by the extrapolation method, as described in ref. [7].
} 
lower than the previously published ones, whereas the second thresholds are in fairly good agreement with the literature. This discrepancy could be due to the low intensity of the ion currents near threshold and the use, in this work, of a more sensitive detection system combined with the first differentiation.

\subsection{Heat of formation of the CS radical}

The shape of the first derivative of the $\mathrm{S}^{+}$ionization efficiency curve close to threshold (fig. 1 a) shows that at $13.35 \mathrm{eV}$ a dissociative ionization process, no ion pair formation is involved, since no peak is detected in the first derivative of the ion current. The first derivative of the retarding curve recorded near threshold (fig. lb) exhibits only one peak centered at thermal energy with a full width at half maximum of $140 \mathrm{meV}$.

When the following reaction is considered

$$
\mathrm{CS}_{2}\left(\mathrm{X}^{1} \Sigma_{\mathrm{g}}^{+}\right)+\mathrm{e}^{-}->\mathrm{CS}\left(\mathrm{X}^{1} \Sigma^{+}\right)+\mathrm{S}^{+}\left({ }^{4} \mathrm{~S}_{\mathrm{u}}\right)_{\mathrm{KE}=0}+2 \mathrm{e}-\text {, }
$$

assuming no internal energy in the fragments, and using the appropriate thermochemical data (IP( $\left.\mathrm{S}^{3} \mathrm{P}_{\mathrm{g}} \rightarrow \mathrm{S}^{+} \mathrm{S}_{\mathrm{u}}\right)$ $=238.89 \mathrm{kcal} \mathrm{mole}^{-1}[8], \Delta H_{\mathrm{f}}\left(S^{3} \mathrm{P}_{\mathrm{g}}\right)=65.7 \mathrm{kcal} \mathrm{mole}^{-1}[9], \Delta H_{\mathrm{f}}\left(\mathrm{CS}_{2}\right)=27.98 \mathrm{kcal} \mathrm{mole}^{-1}$ [9] $)$, one calculates $\Delta H_{\mathrm{ff}}(\mathrm{CS})=31.3 \mathrm{kcal} \mathrm{mole}{ }^{-1}$.

This result is consistent with a recent value we found in a negative ion study [1] $\left(\leq 32 \mathrm{kcal} \mathrm{mole}^{-1}\right)$ and is considerably lower than that deduced by photo-ionization, photoemission spectroscopy and equilibrium kinetic studies.

As shown by the occurrence of a peak at $14.5 \mathrm{eV}$ in the first derivative of the ionization efficiency curve of $\mathrm{CS}^{+}$(fig. 2a), the lowest threshold corresponds to an ion-pair, whereas at $14.7 \mathrm{eV}$ a dissociative ionization process is involved. The $\mathrm{CS}^{+}$ions are formed essentially without kinetic energy in the electron energy range from threshold up to $25 \mathrm{eV}$ (fig. 2b). Using $\mathrm{IP}(\mathrm{CS})=11.33 \mathrm{eV}$ [10], a low value for the appearance potential of $\mathrm{CS}^{+}$is shown to be consistent with a low value for the heat of formation of CS, in this case $40 \mathrm{kcal} \mathrm{mole}^{-1}$, as is also found from the $\mathrm{S}^{+}$measurements. In conclusion, a mean value of $\Delta H_{\mathrm{f}}(\mathrm{CS})=(34 \pm 6) \mathrm{kcal}^{\mathrm{mole}}{ }^{-1}$ is proposed.

\subsection{Dissociation limits}

To interpret the fragmentation processes leading to $\mathrm{S}^{+}$and $\mathrm{CS}^{+}$ions, we need to know the corresponding dissociation limits; using the thermochemical data derived from photoelectron spectroscopy [10], from atomic spectra tables [8] and $\Delta H_{\mathrm{f}}(\mathrm{CS})=(34 \pm 6) \mathrm{kcal} \mathrm{mole}^{-1}$ proposed in this work, we calculate the dissociation limits of $\mathrm{CS}_{2}^{+}$(see table 2). In fig. 3, an energy level diagram is given for $\mathrm{CS}_{2}^{+}$as observed by photoelectron spectroscopy [11], for the Rydberg states of $\mathrm{CS}_{2}$ known from UV absorption spectroscopy [12], for the dissociation limits calculated and the fragments observed in this work.

Table $1: S^{+}$and $C S^{+}$appearance potentials

\begin{tabular}{|c|c|c|c|c|c|c|c|}
\hline \multirow[t]{2}{*}{ Ion } & \multirow{2}{*}{$\begin{array}{l}\text { Photoioniza- } \\
\text { tion }(\mathrm{eV}) \\
\text { ref. }[4]\end{array}$} & \multicolumn{6}{|c|}{ Low energy electron impact $(\mathrm{eV})$} \\
\hline & & ref. [5] & ref. [6] & ref. [17] & ref. [13] & this work ${ }^{\mathrm{a}}$ ) & \\
\hline $\mathrm{S}^{+}$ & & & & & & $\begin{array}{l}13.35 \\
\mathrm{KE} \approx 0\end{array}$ & $\mathrm{~S}^{+}\left({ }^{4} \mathrm{~S}_{\mathrm{u}}\right)+\operatorname{CS}\left(\mathrm{X}^{1} \Sigma^{+}\right)$ \\
\hline & $14.81 \pm 0.03$ & $14.0 \pm 0.5$ & & $14.85 \pm 0.1$ & $15 \pm 1.0$ & 14.55 & $\mathrm{~S}^{+}\left({ }^{4} \mathrm{~S}_{\mathrm{u}}\right)+\operatorname{CS}\left({ }^{1} \Sigma^{+}\right)+E_{\mathrm{vibr}}$ \\
\hline $\mathrm{CS}^{+}$ & & & & & $\mathrm{KE} \approx 0.25$ & $\begin{array}{l}\mathrm{KE} \approx 0 \\
14.5\end{array}$ & $\begin{array}{l}\mathrm{CS}^{+}\left(\mathrm{X}^{2} \Sigma^{+}\right)+\mathrm{S}^{-}\left({ }^{2} \mathrm{P}_{\mathrm{u}}\right) \\
\mathrm{CS}^{+}\left(\mathrm{A}^{2} \Pi\right)+\mathrm{S}^{-}\left({ }^{2} \mathrm{P}_{\mathrm{u}}\right)\end{array}$ \\
\hline & & $14.7 \pm 0.5$ & & & & $\begin{array}{l}\mathrm{KE} \approx 0 \\
14.7 \\
\mathrm{KE} \approx 0\end{array}$ & $\mathrm{CS}^{+}\left(\mathrm{X}^{2} \Sigma^{+}\right)+\mathrm{S}\left({ }^{3} \mathrm{P}_{\mathrm{g}}\right)$ \\
\hline & & $15.7 \pm 0.1$ & $15.35 \pm 0.1$ & & & $15.65 \longrightarrow$ & $\begin{array}{l}-\mathrm{CS}^{+}\left(\mathrm{X}^{2} \Sigma^{+}\right)+\mathrm{S}\left({ }^{1} \mathrm{D}_{\mathrm{g}}\right) \mathrm{CS}^{+}(\mathrm{A} \\
\left.{ }^{2} \Pi\right)+\mathrm{S}\left({ }^{3} \mathrm{P}_{\mathrm{g}}\right)\end{array}$ \\
\hline & 16.16 & & & $16.15 \pm 0.1$ & $16.3 \pm 0.1$ & $\mathrm{KE} \approx 0$ & \\
\hline
\end{tabular}


Fig. 1. (a) First derivative of the ionization efficiency curve of $S^{+}$near threshold. The arrows give the position of the threshold energies listed in table 1. (b) First derivative of the retarding curve of the $\mathrm{S}^{+}$ions at $14.4 \mathrm{eV}$.

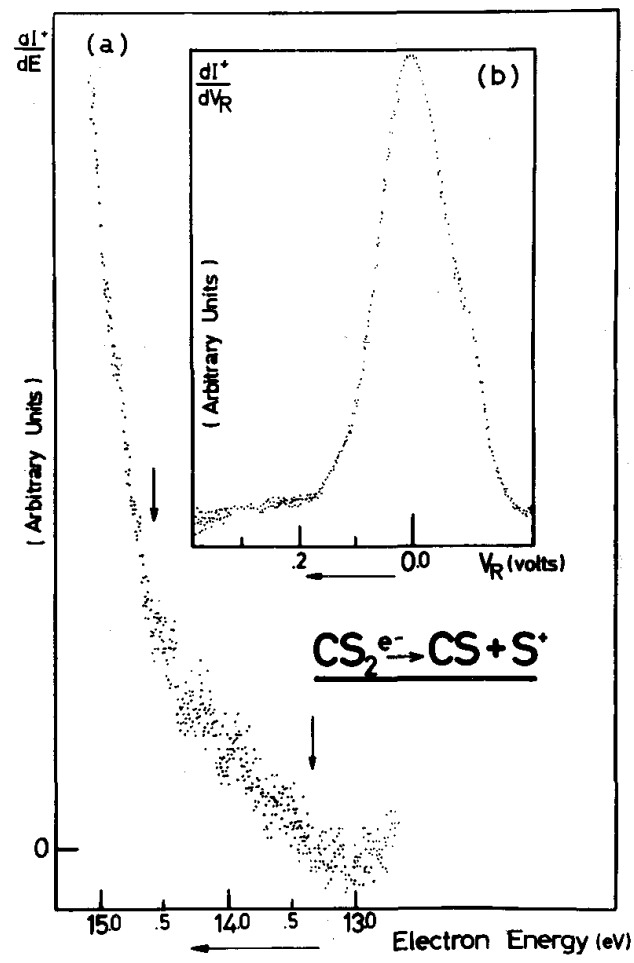

Fig. 2. (a) First derivative of the ionization efficiency curve of $\mathrm{CS}^{+}$near threshold. The arrows give the position of the threshold energies listed in table 1. The peak around $15.5 \mathrm{eV}$ is not a reproducible feature, (b) First derivative of the retarding curve of $\mathrm{CS}^{+}$at $15.9 \mathrm{eV}$.

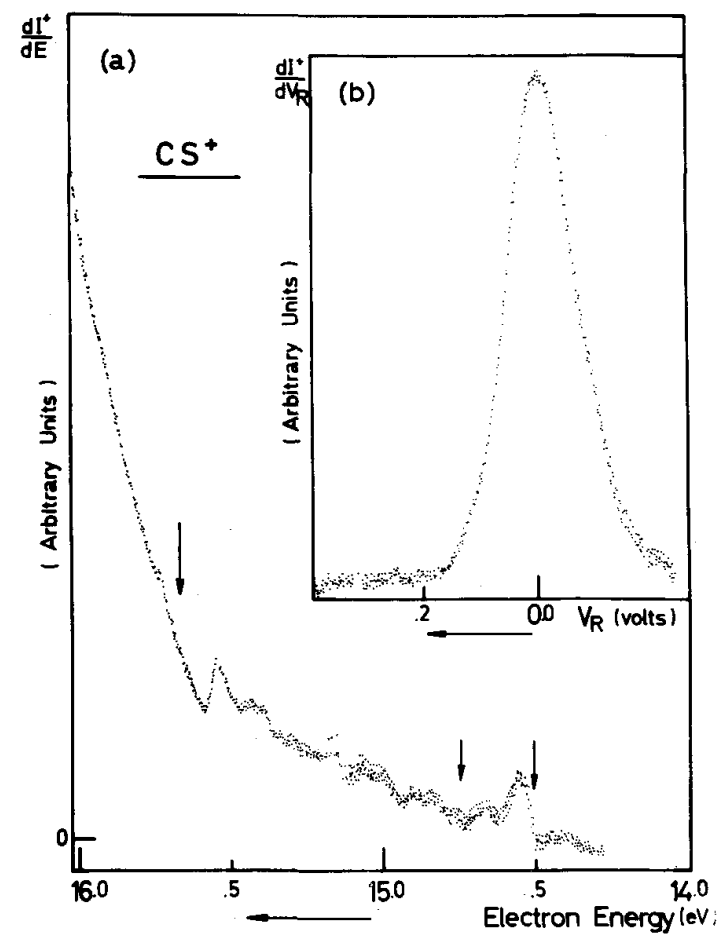


Table 2 : Dissociation limits of $\mathrm{CS}_{2}{ }^{+}$

\begin{tabular}{ccc} 
Fragments & Limits (eV) & Molecular states \\
\hline $\mathrm{S}^{+}\left({ }^{4} \mathrm{~S}_{\mathrm{u}}\right)+\mathrm{CS}\left(\mathrm{X}^{1} \Sigma^{+}\right)$ & $13.61 \pm 0.3$ & ${ }^{4} \Sigma^{-}$ \\
$\mathrm{S}^{+}\left({ }^{2} \mathrm{D}_{\mathrm{u}}\right)+\mathrm{CS}\left(\mathrm{X}^{1} \Sigma^{+}\right)$ & $15.45 \pm 0.3$ & ${ }^{2} \Sigma^{-2} \Pi^{2} \Delta$ \\
$\mathrm{CS}^{+}\left(\mathrm{X}^{2} \Sigma^{+}\right)+\mathrm{S}\left({ }^{3} \mathrm{P}_{\mathrm{g}}\right)$ & $14.40 \pm 0.3$ & ${ }^{4} \Sigma^{-2} \Sigma^{-4} \Pi^{2} \Pi$ \\
$\mathrm{CS}^{+}\left(\mathrm{X}^{2} \Sigma^{+}\right)+\mathrm{S}\left({ }^{1} \mathrm{D}_{\mathrm{g}}\right)$ & $15.55 \pm 0.3$ & ${ }^{2} \Sigma^{+2} \Pi^{2} \Delta$ \\
$\mathrm{CS}^{+}\left(\mathrm{A}^{2} \Pi\right)+\mathrm{S}\left({ }^{3} \mathrm{P}_{\mathrm{g}}\right)$ & $15.80 \pm 0.3$ & ${ }^{2,4} \Sigma_{-}{ }^{2,4} \Sigma^{+2,4} \Pi^{2,4} \Delta$ \\
Ion pair dissociation limits of $\mathrm{CS}_{2}$ & & ${ }^{1,3} \Sigma^{+1,3} \Pi$ \\
$\mathrm{S}^{-}\left({ }^{2} \mathrm{P}_{\mathrm{U}}\right)+\mathrm{CS}^{+}\left(\mathrm{X}^{2} \Sigma^{+}\right)$ & 12.32 & ${ }^{1,3} \Sigma^{+1,3} \Pi^{1,3} \Sigma^{-1,3} \Delta$ \\
$\mathrm{S}^{-}\left({ }^{2} \mathrm{P}_{\mathrm{U}}\right)+\mathrm{CS}^{+}\left(\mathrm{A}^{2} \Pi\right)$ & 13.78 &
\end{tabular}

Fig. 3. Energy level diagram for $\mathrm{CS}_{2}{ }^{+}$as observed by photoelectron spectroscopy [11], for the Rydberg states of $\mathrm{CS}_{2}$ known from UV absorption spectroscopy [12], for the calculated dissociation limits and for the fragments observed in this work.

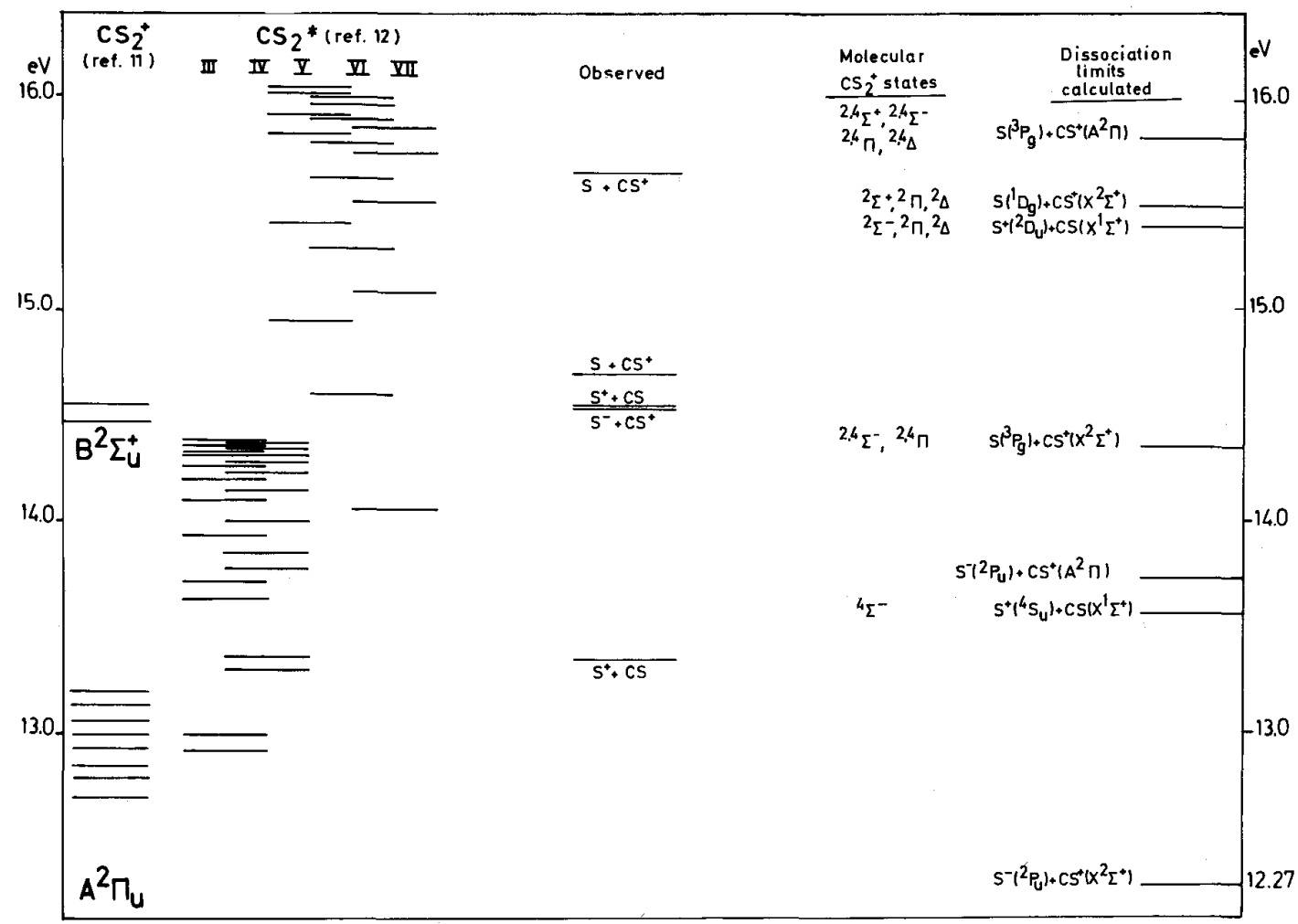

\section{4. $S^{+}$formation}

The ionization efficiency curve of $\mathrm{S}^{+}$recorded in the energy range of $2 \mathrm{eV}$ above the lowest threshold (fig. la) shows two distinct dissociative ionization processes: the first at $13.35 \mathrm{eV}$ and the second at $14.55 \mathrm{eV}$.

The kinetic energy distribution has been measured at different electron energies between threshold and $25 \mathrm{eV}$; only one structureless peak is observed with a maximum at $0.0 \mathrm{eV}$ and a full width at half maximum (fwhm) of $140 \mathrm{meV}$. This fwhm is larger than the $80 \mathrm{meV}$ observed for the distribution of molecular ions. This broadening can only be ascribed to the width of the dissociative ionization process or to unresolved vibrational and/or rotational structure. 
As seen before, the first threshold observed at $13.35 \mathrm{eV}$ is ascribed to process (1) discussed above. According to the correlation rules, the intermediate molecular state must be $\operatorname{CS}_{2}^{+}\left({ }^{4} \Sigma^{-}\right)$.

A second ionization process occurs at $14.55 \mathrm{eV}$, which also leads to $\mathrm{S}^{+}$ions with only thermal energy. As is seen in fig. 3, these ions appear at about $1 \mathrm{eV}$ under the second dissociation limit of $\mathrm{CS}_{2} \cdot$ Reaction (1) and the same ${ }^{4} \Sigma^{-}$molecular ion state have to be invoked in this case, the excess energy being stored as internal motion of the CS radical.

Momigny et al. [13], in an electron impact study of the metastable transitions in $\mathrm{CS}_{2}$, observed at $15 \pm 1$ $\mathrm{eV}$ two kinds of $\mathrm{S}^{+}$ions: one produced by a slow rate decaying metastable molecular state, with a kinetic energy release lower than $0.25 \mathrm{eV}$, the second, in the same energy range, due to a fast rate component. The authors interpreted the first as the result of the predissociation of the $\mathrm{B}^{2} \Sigma_{\mathrm{u}}^{+}$by the ${ }^{4} \Sigma^{-}$state, the second as due to the predissociation of the $\mathrm{X}^{2} \Pi_{\mathrm{g}}$ or $\mathrm{A}^{2} \Pi_{\mathrm{u}}$ by the same ${ }^{4} \Sigma^{-}$state. The present results are consistent with these observations and thus confirm that two processes for the formation of $\mathrm{S}^{+}$occur around $15 \pm 1 \mathrm{eV}$, at 14.55 and $13.45 \mathrm{eV}$, respectively. As Brehm et al. [14] observed in photoion and photoelectron coincidence measurement: that the $\mathrm{X}, \mathrm{A}$ and $\mathrm{B}$ states of $\mathrm{CS}_{2}{ }^{+}$are stable parent ions, the predissociated levels of these states could then be populated by some preionized Rydberg states, lying in this energy range (fig. 3), autoionizing through nonradiative transitions.

\section{5. $\mathrm{CS}^{+}$formation}

The kinetic energy measurements show that the $\mathrm{CS}^{+}$ions appear essentially without kinetic energy from the lowest threshold at $14.5 \mathrm{eV}$ to at least $25 \mathrm{eV}$; this behaviour, which is comparable to that of the $\mathrm{S}^{+}$ions, is shown for $15.9 \mathrm{eV}$ in fig. $2 \mathrm{~b}$ and is the same for the whole energy range analyzed. The lowest threshold corresponds to an ion pair formation, as is seen in fig. 2a by the occurrence of a peak at $14.5 \mathrm{eV}$ in the first derivative of the ionization efficiency curve; this peak is a very reproducible structure, appearing in the averaged (1500 runs) recordings, whereas the little peak at $15.5 \mathrm{eV}$ is a spurious, not reproducible feature. This result is consistent with earlier negative ion measurements performed on an Atlas $\mathrm{CH} 4$ mass spectrometer [15]; sulphur negative ions were shown to be formed by an ion pair process with a threshold estimated at $14.2 \mathrm{eV}$. Using $\mathrm{EA}(\mathrm{S})=2.077 \mathrm{eV}[16]$, the ionization potentials of CS [10] and $\Delta H_{\mathrm{f}}(\mathrm{CS})=34 \pm 6 \mathrm{kcal} \mathrm{mole}^{-1}$, the dissociation limits of the neutral molecule leading to the ion pair are calculated at $12.32 \mathrm{eV}$ for $\mathrm{S}^{-}\left({ }^{2} \mathrm{P}_{\mathrm{u}}\right)+\mathrm{CS}^{+}\left(\mathrm{X}^{2} \Sigma^{+}\right)$and at $13.78 \mathrm{eV}$ for $\mathrm{S}^{-}\left({ }^{2} \mathrm{P}_{\mathrm{u}}\right)+\mathrm{CS}^{+}\left(\mathrm{A}^{2} \Pi\right)$ (fig. 3). The $\mathrm{CS}^{+}$ions observed are formed by one of these reactions, and include some internal energy; the $\mathrm{CS}_{2}$ parent electronic state may be one of the two Rydberg states lying in this energy range: the $n=3$ member of the series $\mathrm{V}$ at $14.47 \mathrm{eV}$ or $n=3$ of the series VII at $14.61 \mathrm{eV}$ [12].

The first dissociative ionization process giving rise to $\mathrm{CS}^{+}$ions has a threshold measured at $14.7 \mathrm{eV}$, which is, within the experimental error on the heat of formation of CS, consistent with the first dissociation limit $\mathrm{S}\left({ }^{3} \mathrm{P}_{\mathrm{g}}\right)+\mathrm{CS}^{+}\left(\mathrm{X}^{2} \Sigma^{+}\right)$calculated at $14.40 \pm 0.3 \mathrm{eV}$. The molecular state could have the following symmetries: ${ }^{4} \Sigma^{-}$, ${ }^{2} \Sigma^{-},{ }^{2} \Pi$ or ${ }^{4} \Pi$. Like the $\mathrm{S}^{+}$ions formed at $14.5 \mathrm{eV}$ through the ${ }^{4} \Sigma^{-}$state, the $\mathrm{CS}^{+}$might be the result of another decay channel of the ${ }^{4} \Sigma^{-}$state. If predissociation of the $\mathrm{B}^{2} \Sigma^{+}$state by the ${ }^{4} \Sigma^{-}$one is also involved in this case, then a slow rate of formation of $\mathrm{CS}^{+}$should be observed as a metastable transition.

At $15.65 \mathrm{eV}$, a second dissociative ionization process leads to an increase of the $\mathrm{CS}^{+}$current. In this energy range, two dissociation limits could contribute to the $\mathrm{CS}^{+}$ions, one at $15.55 \pm 0.3 \mathrm{eV}$ leading to $\mathrm{S}\left({ }^{1} \mathrm{D}_{\mathrm{g}}\right)+$ $\mathrm{CS}^{+}\left(\mathrm{X}^{2} \Sigma^{+}\right)$, the other at $15.86 \pm 0.3 \mathrm{eV}$ leading to $\left.\mathrm{S}^{3} \mathrm{P}_{\mathrm{g}}\right)+\mathrm{CS}^{+}\left(\mathrm{A}^{2} \Pi\right)$. Since no stable molecular ionic state is populated by Franck - Condon transitions in this energy range, we must assume that the dissociating levels result from a population through autoionizing Rydberg states.

\section{Acknowledgement}

Helpful discussions with Professors J. Momigny and J.E. Collin are greatly appreciated. We are indebted to the "Fonds National de la Recherche Scien-tifique" for a research grant (M.-J. H-F.) and to the Belgian "Ministère des Affaires Etrangères, du Commerce Extérieur et de la Coopération au Développement" for a study grant (J.K.). We also gratefully acknowledge the financial support of the "Fonds de la Recherche Fondamentale Collective". 
Published in: Chemical Physics Letters (1976), vol. 37, pp. 488-493

Status: Postprint (Author's version)

\section{References}

[1] M.-J. Hubin-Franskin, J. Katihabwa and J.E. Collin, Intern. J. Mass Spectrom. Ion Phys. (1975), to be published.

[2] G.W. Taylor, J. Phys. Chem. 77 (1973) 124.

[3] D.L. Hildenbrand, Chem. Phys. Letters 15 (1972) 379.

[4] V.H. Dibeler and J.A. Walker, J. Opt. Soc. Am. 57 (1967) 1007.

[5] H.D. Smyth and J.P. Blewett, Phys. Rev. 46 (1934) 276.

[6] L.P. Blanchard and P. le Goff, Can. J. Chem. 35 (1957) 89.

[7] R. Locht and J. Schopman, Intern. J. Mass Spectrom. Ion Phys. 15 (1974)361.

[8] C.E. Moore, NSRDS-NBS 34 (1970).

[9] D.R. Stull, ed., JANAF Thermochemical Tables, 2nd Ed., NSRDS-NBS 37 (1971).

[10] N. Jonathan, A. Morris, M. Okuda, K.J. Ross and D.J. Smith, Faraday Discussions Chem. Soc. 54 (1972) 48.

[11] D.W. Turner, A.D. Baker, C. Baker and C.R. Brundle, Molecular photoelectron spectroscopy (Wiley-Interscience, New York, 1970) pp. 62, 72.

[12] Y. Tanaka, A.S. Jursa and F.J. Leblanc, J. Chem. Phys. 32(1960) 1205.

[13] J. Momigny, G. Mathieu, H. Wankenne and M.A.A. Ferreira, Chem. Phys. Letters 21 (1973) 606.

[14] B. Brehm, J.H.D. Eland, R. Frey and A. Küstler, Intern. J. Mass Spectrom. Ion Phys. 12 (1973) 213.

[15] R. Locht. Doct. Thesis, Liège (1971).

[16] W.C. Lineberger and B.W. Woodward, Phys. Rev. Letters 25 (1970) 424.

[17] J. Momigny and J. Delwiche, J. Chim. Phys. 65 (1968) 1213. 